repeated for three days without a hitch at from 200 to 300 fathoms, the flimsy net emerging from its trials on every occasion with success.

There are two practical points. The first is the art of plunging the net at the surface, the next that of whipping it out on reeling in, so that there may be no contamination of surface organisms during the critical moments. With a highly expert sounding crew such as I had at my service this was easily done.

My repeated experiments were also addressed to this point, viz. to ascertain the best rate of descent and ascent of the net, and my experience was $x$ oo fathoms a minute. The flimsy net stood all tests.

To the modern marine naturalist, whose complicated (and expensive) opening and closing tow-net is an object of worship, this simple advice may seem like telling him to "bathe seven times in Jordan"; he wishes to do a great thing.

February 5.

The Sixth Satellite of Jupiter.

TuE author of the article on the sixth satellite of Jupiter in NATURE of January ig has obviously made a slip in assuming that the "retrograde" motion ascribed to the sate! lite means retrograde in the sky, and not in the orbit. According to the ephemeris, Jupiter on January 4 was moving direct, i.e. eastward, about $225^{\prime \prime}$ daily. The satellite was west of the planet (position angle $269^{\circ}$ ), approaching Jupiter at the rate of $45^{\prime \prime}$ a day, and, therefore, moving eastward (direct) about $270^{\prime \prime}$ daily.

The position angle on January 17 , according to the latest bulletin from Mount Hamilton, was $266^{\circ}$, having decreased $3^{\circ}$; the distance of the satellite had decreased from $45^{\prime}$ to $36^{\prime}$ If the object is really a satellite this necessarily indicates a retrograde orbital motion, unless the plane of its orbit is so much inclined to that of the other satellite-orbits as to make the new one pass north of the planet at inferior conjunction instead of south as the others now do.

The observations thus far published would, however, apply equally well to an asteroid a little within or beyond the orbit of Jupiter, and near perihelion in an orbit of some eccentricity and with a mean distance from the sun somewhat greater than that of Jupiter. We must wait for further observations to determine the truth.

Princeton, N.J., U.S.A., February 3.

\section{The Circulation of the Atmosphere.}

I. HAVE read with great intercst your review of Prof. H. H. Hildebrandsson's report on "The General Motion of Clouds" (NATURe, February 2, p. 329).

All his observations appear to support the theory of my father, the late Prof. James Thomson, as set forth in the Bakerian lecture on "The Grand Currents of Atmospheric Circulation" (Phil. Trans., vol. clxxxiii. p. 653,1892$)$ and in his earlier paper read before the British Association in 1857 .

Is it possible that Prof. Hildebrandsson has not seen these papers, and has accepted theories put forward as Prof. James Thomson's instead of referring to the originals? Anyone who takes the trouble to read these papers carefully must see that it is distinctly stated that the main direction of the upper current of the atmosphere is from west to east while moving steadily and gradually towards the Poles, and that the air keeps this west to east motion as it sinks to a lower level, and becomes the great return current towards the equator. This motion can hardly be termed "vertical circulation." As for Prof. Hildebrandsson's assumption concerning Hadley's theory, I should like to quote the following passage from my father's paper:-

"In 1735 George Hadley submitted to the Royal Society the paper of which I have made mention already as supplying for the first time a substantially true theory of the primarily dominant conditions of atmospheric circulation. The paper is entitled 'Concerning the Cause of the General 'Trade Winds,' and it is right herc to notice that Hadley applied the name 'General Trade Winds' not merely to those winds of equatorial regions to which the name Trade Winds is ordinarily restricted, but uses it as including also the west to east winds known to be prevalent in higher latitudes, and used in trade by mariners NO. I 842 , VOI. 71$]$ for ocean passages from west to east. Thus the scope of his theory must be understood as being much wider than what would be conveyed in ordinary nomenclature by the name Theory of the Trade Winds."

So far then from opposing Hadley's theory, my father's amplifies and completes it.

JAMES THOMSON.

22 Wentworth Place, Newcastle-on-Tyne, February 6.

\section{Remarkable Temperature Inversion and the Recent High Barometer.}

DURING Friday and Saturday, January 27 and 28 , the barometric pressure over the south of England was exceptionally high, readings of 31.00 inches being observed at 6 p.m. on Saturday in the extreme south-west of the country. In the neighbourhood of London the barometer rose to 30.90 during the night of January 26 , and remained at about that height until the morning of January 29 , a well marked anti-cyclone with readings over this value being shown on

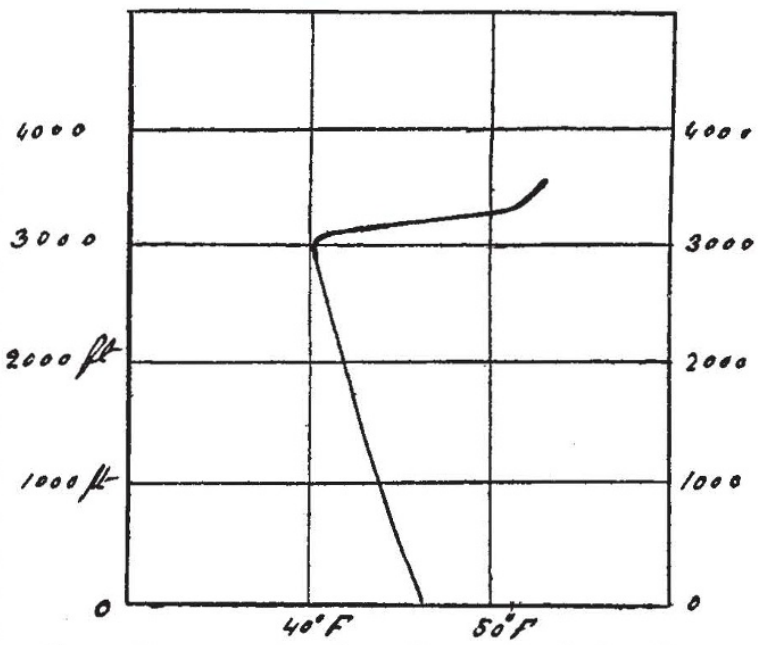

Fig. I: - Temperature inversion on January 28 at Oxshott, Surrey.

the morning and evening weather charts of January 27 and 28 .

During such conditions it is in general impossible to raise a kite, owing to the want or lightness of wind; but on January 28 , during the afternoon, there was sufficient breeze from the west to start a kite carrying recording instruments, and to take them to a height of 3500 feet. A very remarkable temperature inversion was found to exist, the details of which are shown in the accompanying chart. At 3.40 p.m. the surface temperature was $47^{\circ} \cdot 0 \mathrm{~F}$.; at $4.45 \mathrm{p} . \mathrm{m}$. it had fallen to $45^{\circ} \cdot \mathrm{O} \mathrm{F}$. The temperature decreased steadily to $40^{\circ} \mathrm{F}$. at 3000 feet; a little higher a rise of $12^{\circ}$ took place, the temperature at 3300 feet being $52^{\circ}$ F. At 4.28 p.m., at 3600 feet, the temperature was $53^{\circ} \mathrm{F}$. Unfortunately, the humidity trace on the meteorograph partially failed, but it suffices to show that the temperature inversion was, as such inversions in my experience always are, accompanied by extreme dryness of the air.

The wind was west at the surface, and shifted gradually to north-west at the highest point reached, but there was no sudden change of direction at the height where the temperature inversion occurred.

I do not wish to imply that the high barometer and the temperature inversion are necessarily correlated phenomena, but the coincidence is interesting. W. H. Dines.

Dates of Publication of Scientific Books.

With reference to the complaint of Mr. R. P. Paraiypye (p. 320) that a big sum is still asked for Price's "Treatise on Infinitesimal Calculus," I should be obliged if you would allow me to point out that the price of this work is, and has been for some time, $5 s$. a volume.

\section{Henry Frowde.}

Oxford University Press Warehouse, Amen Corner, London, E.C., February 8. 